\title{
Desenvolvimento de material didático instrucional para Geometria Descritiva: uma experiência de design participativo
}

\author{
Development of instructional material for Descriptive Geometry: a participatory design \\ experience
}

\author{
Carlo Alessandro Zanetti Pece, Stephania Padovani, Diego Mafioletti, Anna Carolina Murata \\ Galeb, Pedro Serigheli da Rocha Paranhos
}

Material didático, Geometria Descritiva, design participativo

\begin{abstract}
O presente estudo tem como objetivo desenvolver, através de uma abordagem de design participativo, material didático instrucional para o ensino de GD, particularmente voltado a alunos de cursos de Design. Para tal, realizou-se inicialmente uma revisão bibliográfica sobre o ensino de Geometria Descritiva, enfocando principalmente o papel das representações gráficas no aprendizado dos conceitos e princípios desse domínio. A produção do material didático ocorreu no contexto da própria disciplina de GD, ou seja, os próprios alunos, orientados pelo professor, realizaram anotações e propuseram sugestões do que poderia ser melhorado no material. Sendo o material desenvolvido mais dinâmico, os alunos sentiram-se estimulados e, consequentemente, mais motivados para o estudo de GD. Observou-se uma ampliação do diálogo discentediscente, assim como discente-docente sobre a disciplina, surgindo frequentemente propostas de melhoramento. Essas propostas vêm sendo discutidas, dentre as quais destaca-se a criação de artefatos concretos, demonstrando aspectos básicos da disciplina. O material reformulado continua sendo utilizado pelas turmas subseqüentes de Geometria Descritiva, assim como referência para outras disciplinas relacionadas.
\end{abstract}

Instructional material, Descriptive Geometry, participatory design

This study aims to develop, by means of a participatory design approach, instructional material for DG teaching, particularly meant for Design students. In order to achieve such purpose, we initially conducted a literature review about Descriptive Geometry teaching, focusing on the role of graphic representations on the learning of concepts and principles from such knowledge domain. The material was developed within the context of the classroom, when the students, supervised by the teacher, reported their impressions and proposed suggestions to improve the material. Since the material turned out to be more dynamic, students felt stimulated and, consequently, more motivated to study DG. The dialogue between students and the teacher also improved, and several proposals have emerged so far. These proposals have been discussed, among which the main idea is to create concrete artefacts, demonstrating basic aspects of DG. The instructional material is currently being used by new DG students and as a reference for related contents.

\section{Introdução}

Todo projeto de design necessita ser representado graficamente para que possa ser traduzido de seus aspectos conceituais para seus aspectos concretos / materiais, ou seja, construído. A representação gráfica pode ser considerada o elemento constitutivo básico no diálogo entre quem projeta e quem executa o projeto. Conforme adverte Valente (2003), no entanto, para que essa comunicação gráfica seja eficiente, a representação deve ser precisa, ou seja, as imagens descritivas em superfície plana devem representar de maneira clara, inequívoca e com exatidão os objetos tridimensionais.

Devido a sua comprovada importância, a representação gráfica de projetos é parte essencial da grade curricular de cursos de Design generalistas e habilitações de Projeto de Produto no país. Alguns desses cursos incluem no rol das disciplinas associadas à representação algumas de fundamentação, como, por exemplo, a Geometria Descritiva.

Geometria Descritiva pode ser definida como a ciência que tem por finalidade representar em um plano as figuras do espaço de maneira que, nesse plano, possam ser resolvidos todos os problemas relativos a essas figuras (PRÍNCIPE JÚNIOR, 1983). A Geometria Descritiva como disciplina faz parte da grade curricular de cursos de $3^{\circ}$ grau principalmente nas áreas das ciências exatas e tecnológicas, como por exemplo, as engenharias. No Brasil, alguns cursos de Design e 
Arquitetura também a incluem como disciplina específica ou como parte do conteúdo de disciplinas relacionadas a métodos de representação gráfica de projetos.

Segundo Vieira (2005), a Geometria Descritiva (GD) visa o aperfeiçoamento da visualização espacial por parte dos alunos, habilidade essa primordial para as profissões que serão posteriormente desenvolvidas por estes alunos. Entretanto, pesquisas anteriores identificaram dificuldades de visualização durante a aprendizagem de GD por estudantes universitários. Os principais fatores associados a essas dificuldades são a falta de conhecimentos prévios específicos de desenho no ensino médio (VIEIRA, 2005) e a excessiva importância atribuída às características de traçados extremamente técnicos, em detrimento do processo cognitivo utilizado pelo aluno para o aprendizado dos conceitos e propriedades em GD (BULHÕES, 2004; GONÇALVES, 2005).

Acrescente-se a essa problemática questões metodológicas relacionadas à prática docente, conforme as observadas por Gonçalves e Ulbricht (2006). Em investigação realizada na UFSC, as pesquisadoras constataram, em contato com os responsáveis pelas disciplinas de GD, que muitos ainda ministravam suas aulas utilizando a mesma metodologia desde que haviam ingressado na docência. Observou-se ainda que os únicos materiais de apoio utilizados eram um diedro de madeira, alguns palitos e pedaços de cartolina, mas nada sistematizado.

Recentemente, uma série de pesquisadores de diversas áreas do conhecimento tem buscado soluções para os problemas anteriormente apontados através das Tecnologias de Informação e Comunicação (TICs). Valente e Santos (2004), por exemplo, desenvolveram um ambiente computacional customizável para apoio ao ensino de GD. Vieira (2005), por sua vez, adaptou um ambiente hipermidiático (Visual GD) para o ensino de GD para alunos surdos. Silva et al. (2006) desenvolveram um conjunto de objetos de aprendizagem para a Geometria Descritiva passíveis de utilização tanto no ensino presencial quanto à distância. Uma análise da literatura nos permite observar, entretanto, que a grande maioria das iniciativas se concentra em materiais digitais ou ambientes de aprendizagem virtuais, existindo uma carência de pesquisas que enfoquem o desenvolvimento e/ou avaliação de material didático instrucional impresso para a disciplina de GD.

Nesse contexto, este estudo tem como objetivo desenvolver, através de uma abordagem de design participativo, material didático instrucional em formato impresso para o ensino presencial de GD, particularmente voltado a alunos de cursos de Design.

\section{O Ensino de Geometria Descritiva: contextualização}

\subsection{Habilidades cognitivas a serem desenvolvidas pelos alunos no estudo da GD}

Segundo Valente (2003), os objetivos principais a serem alcançados no estudo da Geometria Descritiva são: (a) o desenvolvimento da visão espacial, (b) a capacidade de representar elementos tridimensionais no plano, indicando corretamente sua forma, tamanho e posição relativa, (c) capacidade de interpretar representações gráficas no plano e (d) resolver problemas geométricos espaciais no plano. Valente (2003) afirma ainda que as competências cognitivas a serem desenvolvidas em GD devem ser galgadas de forma evolutiva, conforme representado na figura 1.

$\mathrm{Na}$ abordagem convencional, segundo Valente (2003) o aluno necessita inicialmente conhecer conceitos, nomenclaturas, definições e notações, além dos elementos geométricos básicos com os quais irá trabalhar. De posse desses conhecimentos, torna-se possível iniciar a compreensão das propriedades desses elementos geométricos e suas projeções.

O próximo estágio envolve a aplicação das projeções aprendidas em épura, planos auxiliares e a solução dos primeiros problemas envolvendo GD e representação gráfica. A repetida solução de problemas de GD faz com que o aluno desenvolva capacidades de análise e síntese, ou seja, entenda melhor as representações e inclua em seu repertório um conjunto de procedimentos geométricos passíveis de aplicação em problemas de GD.

Por fim, o estágio final desse desenvolvimento compreenderia a capacidade de propor soluções otimizadas para os problemas de GD, sendo capaz de avaliar suas próprias soluções ou aquelas propostas em exercícios resolvidos. 


\section{Infodesıgn}

Figura 1: Competências cognitivas a serem desenvolvidas no estudo de GD (fonte: Valente, 2003)

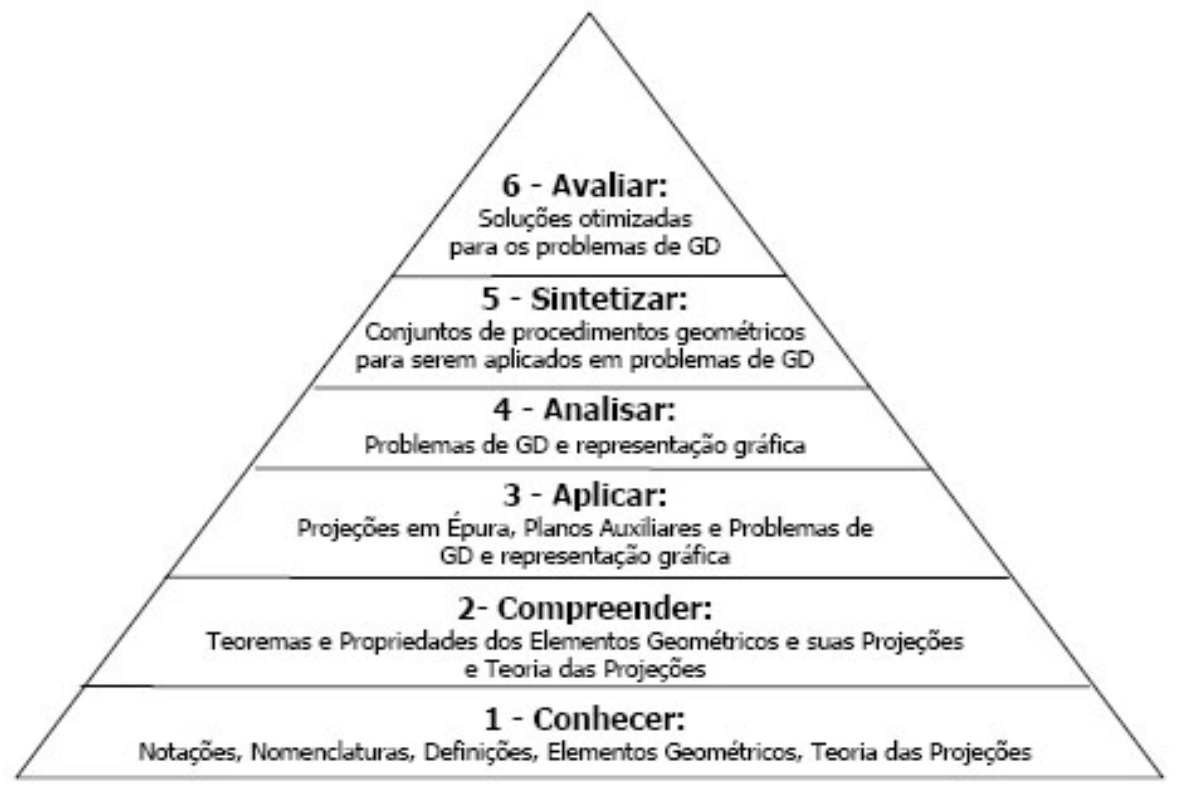

\subsection{O papel das representações gráficas no aprendizado de GD}

Conforme discutido anteriormente, o aprendizado de GD envolve o desenvolvimento de habilidades relacionadas tanto à produção quanto à interpretação de representações gráficas. Cabe, portanto, ao iniciar nossa reflexão sobre o papel das representações gráficas em GD, esclarecer conceitualmente o termo representação gráfica.

Segundo Engelhardt (2002) representação gráfica pode ser definida como um artefato visível em uma superfície relativamente plana, criado com o objetivo de expressar informação. Um aspecto importante a ser enfatizado na definição proposta por Engelhardt é a bidimensionalidade do suporte. Nesse sentido, o autor ressalta que, apesar do meio de visualização ser bidimensional, o objeto sendo representado pode ter caráter tridimensional.

Conforme explicado por Gonçalves e Ulbricht (2006), no ensino da Geometria Descritiva, o estudante deve imaginar (criar uma representação mental) o objeto real tridimensional a partir de suas projeções no plano, ou seja, há uma constante tradução entre o bidimensional e o tridimensional. Jacques et al. (2001) sintetizam esta característica da GD como "a união da compreensão tridimensional com a representação bidimensional" e explicam que o estudo de GD tem início pela compreensão dos entes fundamentais, ponto, reta e plano, em relação a um sistema de projeções que se caracteriza pela planificação do espaço (figura 2).

Figura 2: Plano oblíquo com linhas projetantes e projeções, seguido da planificação do sistema (épura) (fonte: Jacques et al., 2001)
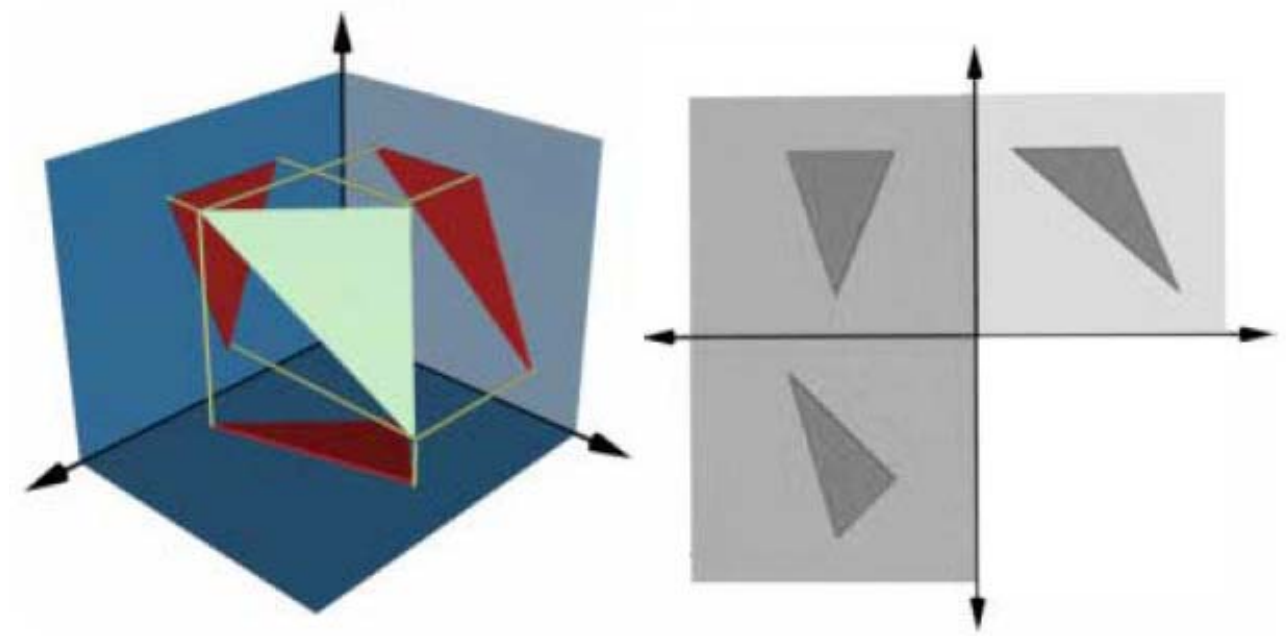

Um outro aspecto fundamental do aprendizado da GD é o desenvolvimento da capacidade 
analítica, ou seja, a habilidade de desconstruir objetos mais complexos em seus entes fundamentais. Conforme explica Kopke (2001), ao observarem sólidos ou objetos, os alunos necessitam perceber que, na realidade, devem representar, no desenho, suas faces, arestas e vértices, estando aí contidos os planos, retas e pontos abordados na metodologia convencional da Geometria Descritiva (figura 3).
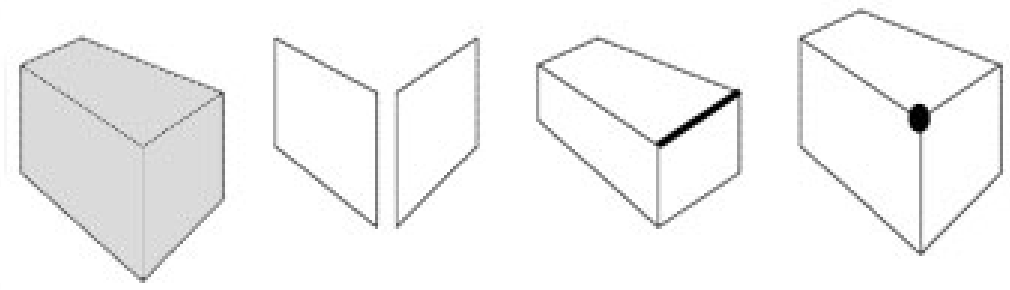

Um outro aspecto particular da produção de representações gráficas durante o aprendizado de GD refere-se à importância de seu caráter processual. Segundo Santos (1999), uma das grandes dificuldades de aprendizado da GD está associada à perda do sequenciamento das construções geométricas, pois a ordem das operações realizadas não fica explicitamente representada quando o aluno observa a forma final de um exercício resolvido. Principalmente exercícios complexos, após sua resolução, podem resultar num grande número de linhas e pontos, tornando difícil a compreensão do procedimento realizado (figura 4).

Figura 4: Exemplo da representação gráfica resultante da solução de um exercício de GD (fonte: Santos, 1999)

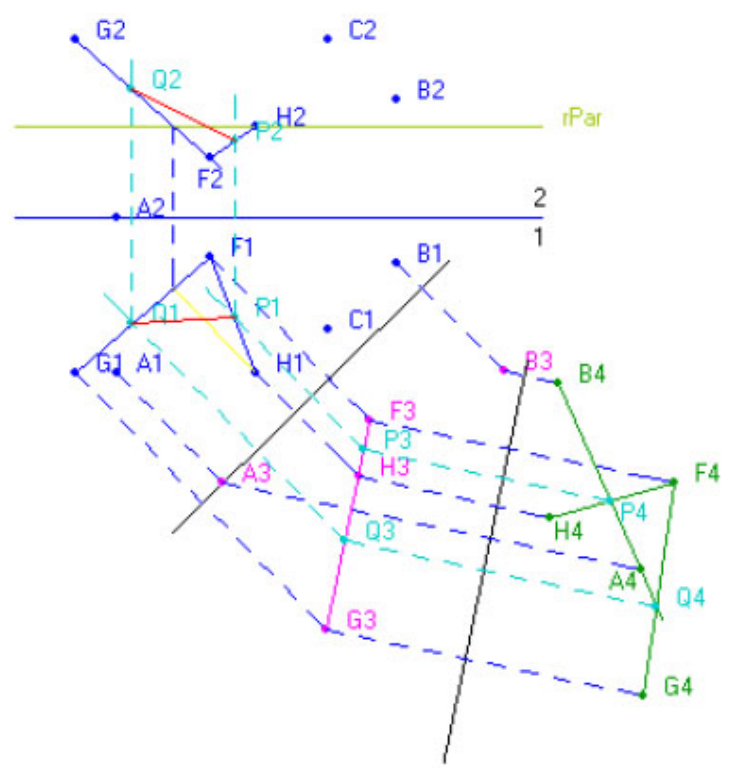

Quanto à ênfase comunicacional das representações gráficas, Engelhardt reforça que sua principal intenção é descrever, explicar, instruir. Comunicar, numa acepção mais ampla significa transmitir sem ambigüidade determinada mensagem. No caso da Geometria Descritiva, esse aspecto encontra-se intrinsecamente ligado à utilização de notações e formas de projeção padronizadas não necessariamente intuitivas para a maioria dos alunos. Desse modo, o aluno precisa "re-educar o seu olhar" e desenvolver o pensamento abstrato, para conseguir enxergar os objetos de uma maneira diferente das formas de representação mais literais e/ou realistas empregadas pelo design (e.g., sketches, renderings, modelos virtuais 3D).

Por fim, cumpre recordar os últimos estágios do desenvolvimento de competências cognitivas descritos por Valente (2003): aquisição de um conjunto de procedimentos geométricos passíveis de aplicação em problemas de GD, capacidade de propor soluções otimizadas para os problemas de GD e de avaliar suas próprias soluções ou aquelas propostas em exercícios resolvidos. A solução de problemas, conforme explica Matlin (2004), envolve três estágios principais: (a) seleção e atenção a informações relevantes, (2) representação do problema e (c) seleção de estratégias de solução com base em critérios. A representação do problema somente se torna InfoDesign Revista Brasileira de Design da Informação 6 - 1 [2009] 1-1] ISSN 1808-5377 


\section{Infødesıgn}

possível quando a pessoa desenvolveu uma compreensão suficiente para transformar conceitos e proposições abstratas em algo visualizável, ou seja, externalizar seus pensamentos. O uso de representações na solução de problemas é fundamental pois permite liberar a memória de curta duração para realizar a comparação entre as estratégias de solução que se apresentam. Entretanto, para que isto seja possível, a (de)codificação da representação deve ser o mais transparente possível, permitindo que os recursos cognitivos sejam efetivamente empregados na solução do problema em questão.

Todas essas características, aliadas à necessidade de operacionalização dos conceitos principais da Geometria Descritiva, resultam em um árduo esforço de abstração por parte do aluno, que, até o momento, não está familiarizado com o tipo de representação adotado na disciplina. Exige-se, portanto, do estudante o desenvolvimento de sua percepção e visualização espacial, habilidades essas que também serão requisitadas em outras disciplinas que envolvem a representação de projetos por intermédio de vistas ortográficas (e.g., desenho técnico).

\subsection{Alternativas para a melhoria do ensino de GD}

O reconhecimento das dificuldades envolvidas no aprendizado de GD nos cursos de projeto tem motivado pesquisadores de diversas áreas a buscar alternativas visando a melhoria do ensino de GD em suas instituições. Essas iniciativas incluem desde mudanças de caráter metodológico até o desenvolvimento de material didático digital ou mesmo de ambientes virtuais próprios para o ensino de GD.

No âmbito metodológico, cumpre citar as iniciativas de Kopke (2001), Teixeira et al. (2006) e Silveira (2007). Kopke (2001) desenvolveu uma nova metodologia para o ensino de GD que propõe a inversão da ordem em que os conteúdos são abordados tradicionalmente. Ao invés de iniciar com pontos, retas e então planos, a autora experimentou trabalhar inicialmente com a representação (em livre formato) de objetos familiares aos alunos. A partir do desenho desses objetos, propôs então sua desconstrução em elementos básicos. A forma de apresentação dos exercícios (figura 5) também foi trabalhada pela autora no sentido de estimular o uso da cor e de outros mecanismos gráficos que facilitassem a diferenciação e aumentassem o interesse dos alunos.

Figura 5: Detalhe de um exercício utilizando codificação cromática (fonte: Kopke, 2001)

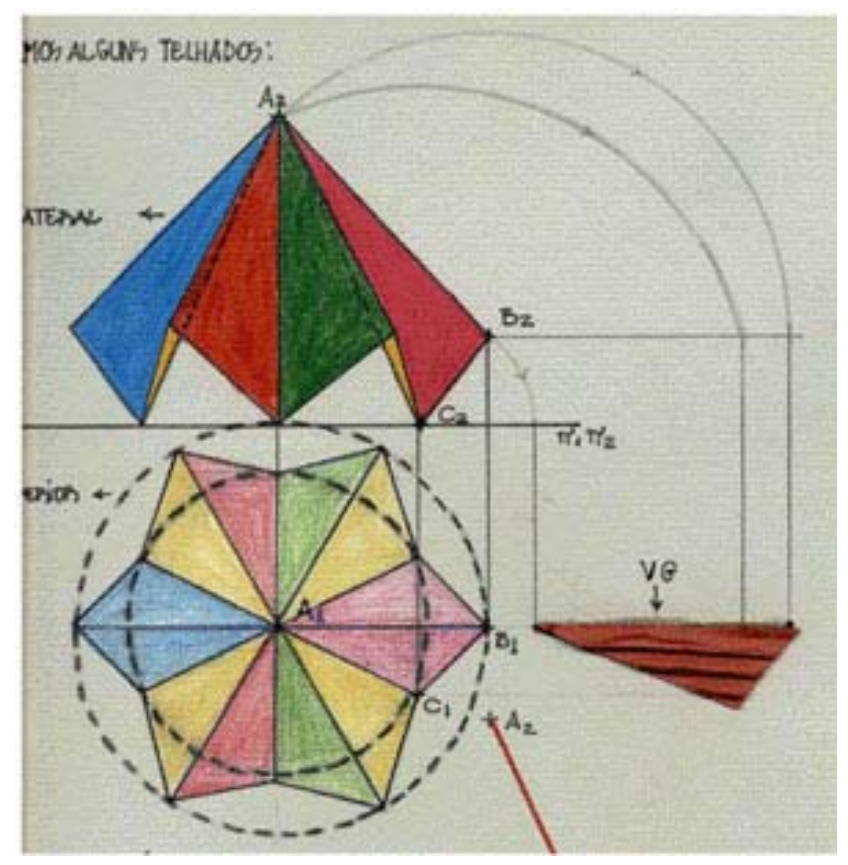

Teixeira et al. (2006) instituíram uma metodologia para ensino da geometria descritiva fundamentada em uma nova abordagem conceitual e no uso da aprendizagem baseada em projetos (design-based learning). As principais alterações em relação às abordagens tradicionais foram: (a) apresentação dos conceitos fundamentais através do estudo de sólidos, (b) uso do conceito de interseção entre planos como ferramenta de modelagem (corte de sólidos e geração de geometrias mais complexas), (c) planificação e construção de modelos reais. A sistemática do design-based learning utiliza um conjunto de projetos que têm como objetivo o desenvolvimento 
de formas sólidas buscando compatibilizar uma série de requisitos e restrições. Na etapa inicial, utilizam-se formas sólidas simples e com verdadeiras grandezas em projeções sobre os planos principais. Já na etapa mais avançada, são propostos projetos que apresentam faces oblíquas, onde são necessárias duas mudanças de sistema de referência para encontrar as verdadeiras grandezas.

Silveira (2007) propôs uma reformulação para a metodologia de ensino de GD em cursos de arquitetura. Para apresentar a classificação de planos e retas, por exemplo, foram usados modelos tridimensionais que poderiam se tornar objetos arquitetônicos. Em interseções de planos foram trabalhados desafios para soluções de coberturas e no estudo de sombra foram usadas plantas e fachadas, antecipando desafios da profissão. Foram confeccionados conjuntos de sólidos, cuja manipulação sempre antecede os desenhos das épuras em sala de aula, ou seja, o aluno conta com o modelo tridimensional para esclarecimento da épura. Parte-se, portanto, de um modelo espacial, passa-se para o desenho da planificação das vistas, retornando ao modelo tridimensional para conferência.

Figura 6: Exemplos de representações bidimensionais e modelo físicos utilizados na solução de problemas de GD (fonte: Silveira, 2007)

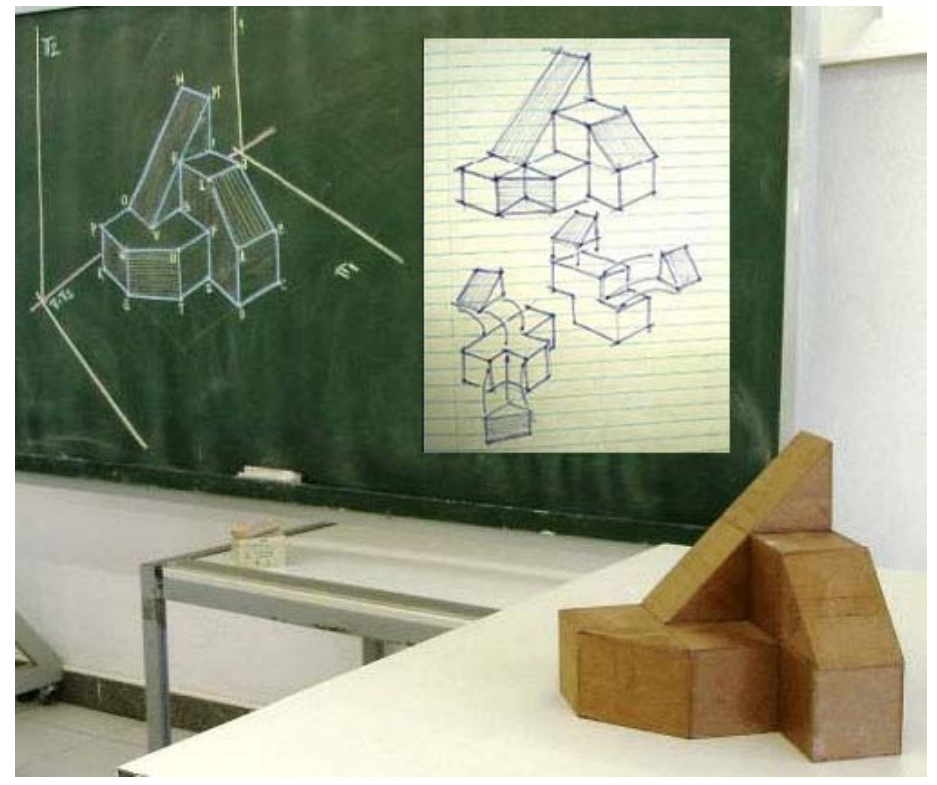

No âmbito da criação de material didático digital e desenvolvimento de ambientes virtuais de aprendizagem, merecem menção as iniciativas de Gonçalves e Ulbricht (2006), Lima e Costa (2007) e Valente e Santos (2004).

Gonçalves e Ulbricht (2006) apresentaram o programa denominado Visual GD, o qual utiliza a metáfora de um escritório de projetos. Nele estão presentes os elementos do cotidiano de um arquiteto ou engenheiro. O sistema simula a entrada do usuário no escritório até que este recebe uma tarefa. Assim ele acaba "sentando-se na prancheta" para então iniciar seu trabalho. Assim a tela assume aparência de uma prancheta. Nela estão contidos todos os elementos de navegação (avanço e recuo de páginas, saída, impressão) além de outras ferramentas que auxiliam o estudante no decorrer de seu estudo (ferramentas de visualização dos objetos em 2D e 3D, fluxograma dos conteúdos abordados com marcação daqueles que já foram estudados, etc.). Os conteúdos inseridos na versão atual do Visual GD são referentes à Projeção Cilíndrica Ortogonal e estudo de ponto, reta e plano. 


\section{Infodesıgn}

Figura 7: Exemplo de tela do VISUAL GD (fonte: Vieira, 2005)

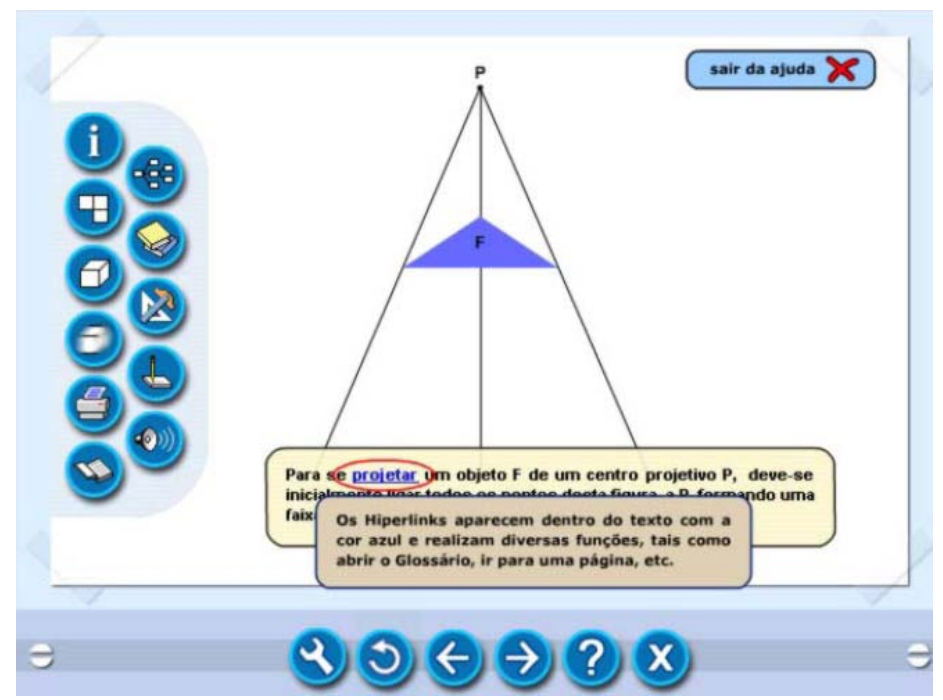

Lima e Costa (2007) desenvolveram um software para o ensino de GD que permite ao aluno experimentar os parâmetros que configuram a forma (posição, direção, projeção cônica ou cilíndrica), além de explorar parâmetros que controlam o estilo das linhas (espessura e tracejado), buscando aqueles que seriam usados para identificar objetos ocultos, linhas auxiliares e contornos nas épuras a serem construídas posteriormente. O programa possui ainda uma espécie de "magnetismo" na malha quadriculada que mostra as coordenadas dos pontos. Isso significa permitir ao usuário, com o movimento do mouse, escolher facilmente os pontos que têm coordenadas inteiras. Encontra-se em desenvolvimento uma ferramenta de detecção automática das partes ocultas de um objeto (visibilidade), fornecendo ao aluno um meio de verificar a visibilidade dos traços presentes em uma determinada construção.

Figura 8: Exemplo de tela do software para ensino de GD desenvolvido por Lima e Costa (2007)

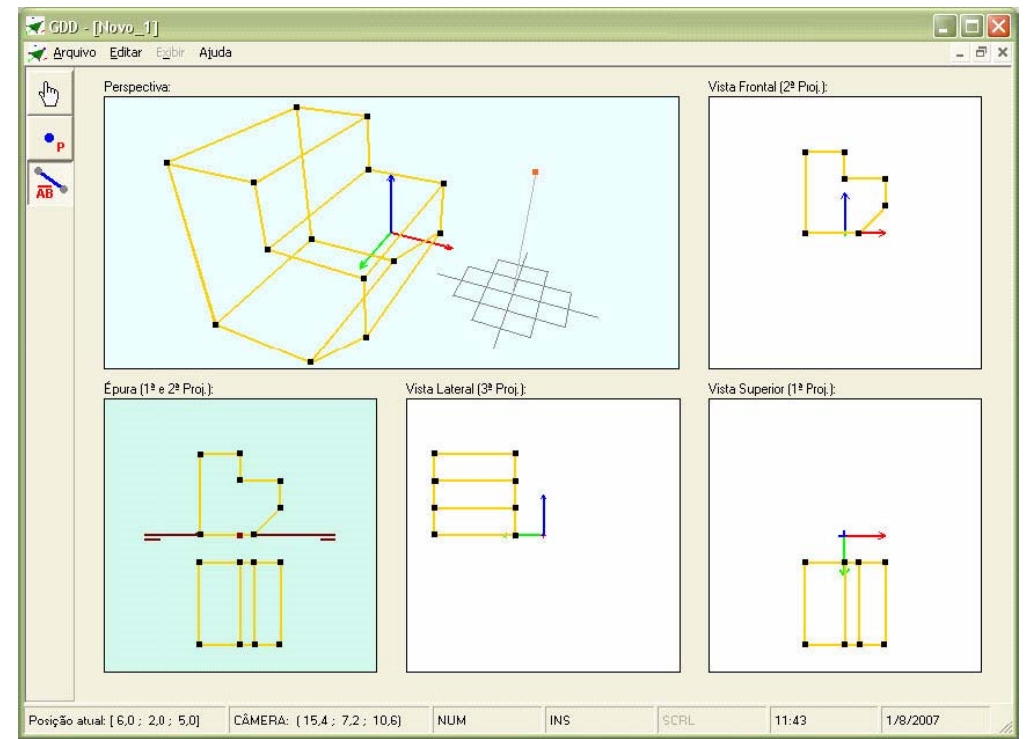

Valente e Santos (2004) desenvolveram um Ambiente Computacional de Suporte ao Aprendizado de Geometria Descritiva (GD) capaz de se adaptar às necessidades de aprendizagem do aluno. No sistema proposto, o aluno interage via Internet e desenvolve seu aprendizado por meio da resolução de exercícios. Este ambiente tem como suporte uma biblioteca de exercícios de GD e sugere caminhos para conduzir o aprendiz a níveis cada vez mais aprofundados em seus estudos. O referido ambiente de aprendizagem também oferece um repositório de exercícios de GD que pode ser acessado e incrementado por professores. 
e Santos, 2004)

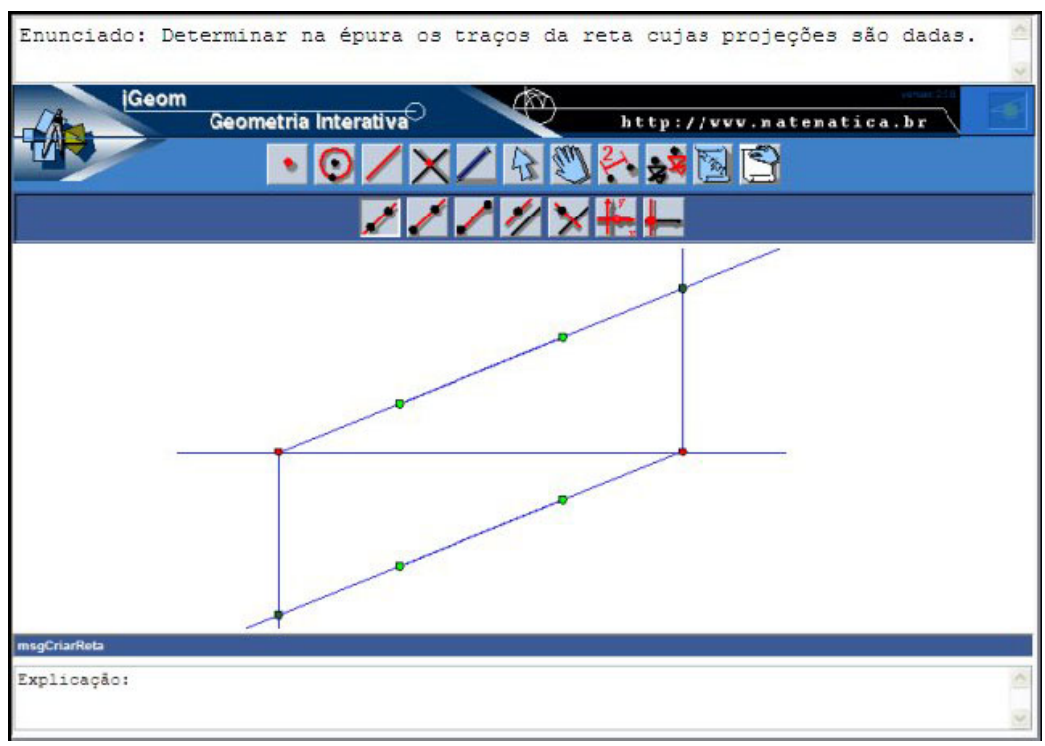

\section{Método}

\subsection{Design participativo}

De acordo com Cybis [2003], o envolvimento do usuário pode trazer importantes benefícios para o design de sistemas de informação. O autor identificou três tipos básicos de envolvimento do usuário no processo de design: informativo, consultivo e participativo. No envolvimento informativo, o usuário é visto como fonte de informação, ou seja, fornece informações que serão transformadas em requisitos de projeto. Já no envolvimento consultivo, o usuário é consultado diretamente sobre decisões de projeto, para que ele as verifique e emita opinião sobre as mesmas. Por fim, o envolvimento participativo pode ser considerado o nível mais elevado de envolvimento do usuário, visto que a responsabilidade do projeto é compartilhada com o usuário durante todo o processo (e.g., geração de requisitos, conceituação, detalhamento, avaliação). Neste estudo adotamos uma abordagem participativa, na qual os alunos da disciplina de Geometria Descritiva participaram ativamente na crítica, proposição e implementação de soluções informacionais e gráficas para o material didático.

\subsection{Participantes}

Vinte e nove alunos de duas turmas de primeiro período do curso de Bacharelado em Design da Universidade Tecnológica Federal do Paraná (UTFPR) matriculados na disciplina de Geometria Descritiva 1 participaram mais efetivamente deste estudo. Os alunos trabalharam geralmente em duplas, ficando cada dupla responsável pela adequação de pelo menos um módulo do conteúdo programático.

\subsection{Procedimento}

A reformulação do material didático instrucional ocorreu no decorrer da própria disciplina de GD, ou seja, à medida que os alunos interagiam com o material antigo para aprender algum conteúdo, identificavam necessidades de reformulação. Assim, no decorrer das aulas, os próprios alunos, orientados pelo professor da disciplina, realizaram anotações e propuseram sugestões preliminares do que poderia ser melhorado nos módulos, formulando perguntas quando a solução não se apresentava imediatamente. Para o redesign do material didático original, foi utilizado como base o modelo de Garrett (2003), considerando-se apenas os aspectos aplicáveis a sistemas de informação em suporte impresso (figura 10). 


\section{Infødesıgn}

Figura 10: Atividades de redesign do material didático conforme modelo de Garrett (2003).

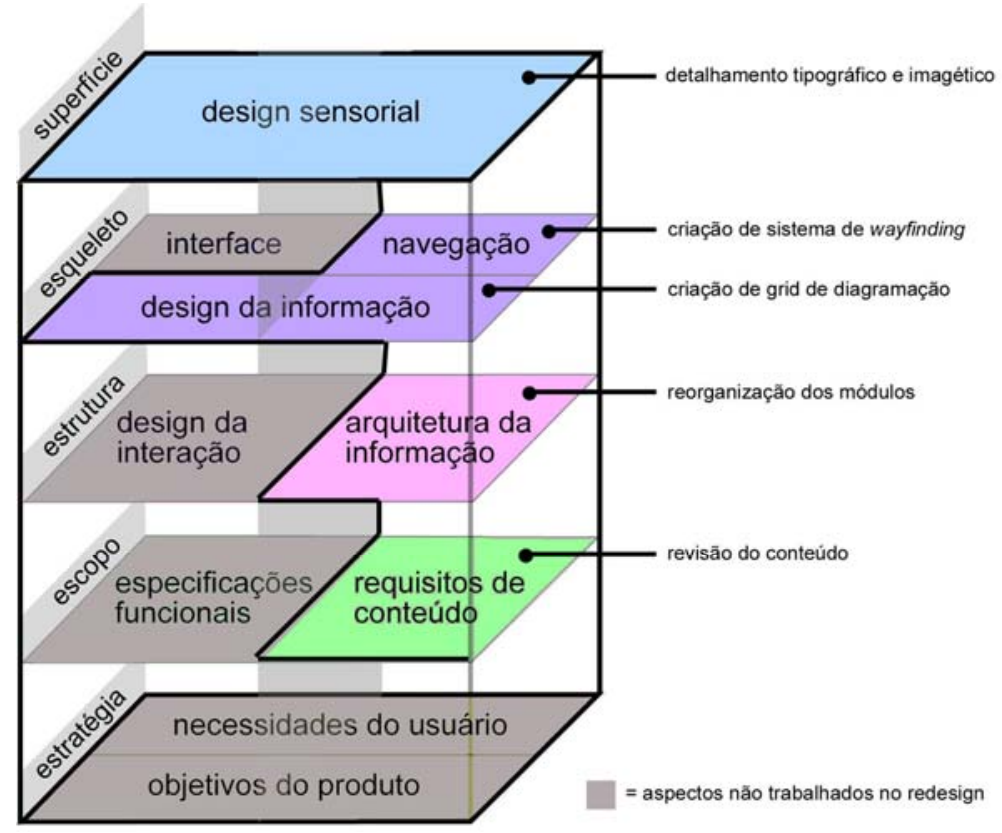

\subsection{Material didático original e abordagem pedagógica}

O material didático que sofreu reformulação foi proposto e cedido por Ulbricht (1997), sendo composto de 13 módulos de natureza teórico-prática com apoio de sólidos geométricos concretos simples. Ulbricht (1997) propõe também atividades complementares no software Visual GD. Os sólidos geométricos foram construídos pelos próprios alunos, que, dentre as tarefas previstas, precisavam imaginar como estes seriam planificados para então colocá-los no papel e montá-los.

O material proposto pela autora baseia-se, principalmente, na metodologia de resolução de problemas, estimulando o aluno a buscar soluções e promover o auto-aprendizado. Almeja-se, literalmente, construir o aprendizado. O professor é, pressupostamente, um facilitador a maior parte do tempo, havendo, no entanto, momentos aonde sua interferência faz-se necessária. A abordagem utilizada envolve inicialmente a visualização mental, seguida da formalização física e, posteriormente, conceituação teórica. Na fase inicial, os cinco primeiros módulos, o aluno é "sensibilizado". Os conceitos básicos e notação são introduzidos aos poucos como fruto da necessidade. Posteriormente, são abordados tópicos mais específicos de GD. Os conteúdos abordados nos módulos são:

[1] Definição de geometria descritiva, de sistemas de projeção e de épura;

[2] Projeção experimental de sólidos

[3] Princípios básicos da geometria descritiva;

[4] Estudo de planos;

[5] Pertinência de figuras a planos;

[6] Retas específicas e seus traços;

[7] Pertinência de reta e ponto a plano e plano dado por pontos e retas;

[8] Retas paralelas e concorrentes;

[9] Retas de máximo declive e máxima inclinação;

[10] Determinação de retas sem o traço dos planos;

[11] Coordenadas;

[12] Interseção de planos; e

[13] Métodos descritivos: rebatimento, alçamento e rotação. 


\section{Resultados}

O material didático original, durante o processo de redesign passou por reformulação teórica, reconstrução e padronização de imagens, correção dos textos e enunciados (quanto à coesão e coerência), além da seleção e substituição de exercícios. Nesta sessão apresentamos alguns exemplos de partes do material antes e após o redesign.

Houve ainda a inclusão de um glossário, das referências bibliográficas, de uma pequena coleção de sólidos planificados para exemplificação dos respectivos processos, além de agradecimentos e de uma calorosa introdução dos veteranos aos futuros calouros.

Com relação à estrutura do material, houve, por questões curriculares, a retirada de um dos módulos originais supramencionados. No entanto, a experiência demonstrou ser melhor a reintrodução deste módulo ao corpo principal do texto.

No plano do esqueleto (quarta etapa do modelo de Garrett, 2003), os alunos propuseram uma nova grid de diagramação e tornaram mais evidente o sistema de wayfinding existente no material, sinalizando sempre o módulo em que o leitor se encontra. Também criaram páginas de abertura para cada módulo com imagens que remetem ao conteúdo do mesmo.

Figura 11: Detalhe de uma página do material antigo e sistema de wayfinding (pouco destacado) na parte superior

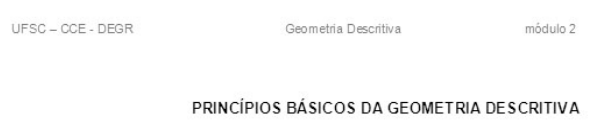

Voltemos aos resultados obtidos por você com as projeçốes do paralelepípedo. Verificamos, por exemplo que uma mesma aresta é projetada em duas direções: uma em relação ao $\pi$, e outra, em relação ao $\pi$ perpendicular ao plano de projecão onde a figura será projetada. Assim, toda figura, reta ou ponto projetada, ortogonalmente, em cada um do planos. 


\section{Infodesıgn}

Figura 12: Página do material reformulado e sistema de wayfinding na lateral esquerda e parte inferior

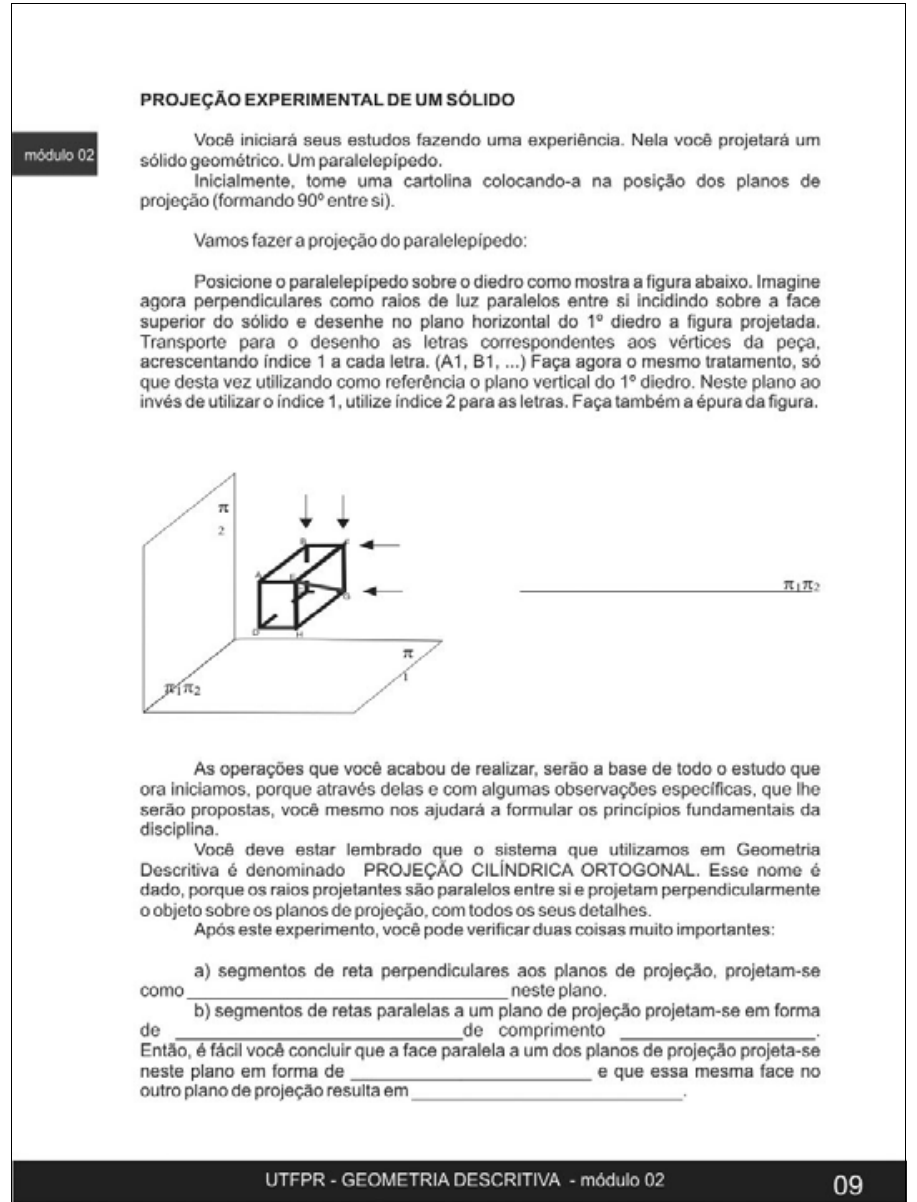

Figura 13: Exemplo de página de abertura do módulo 2 do material reformulado

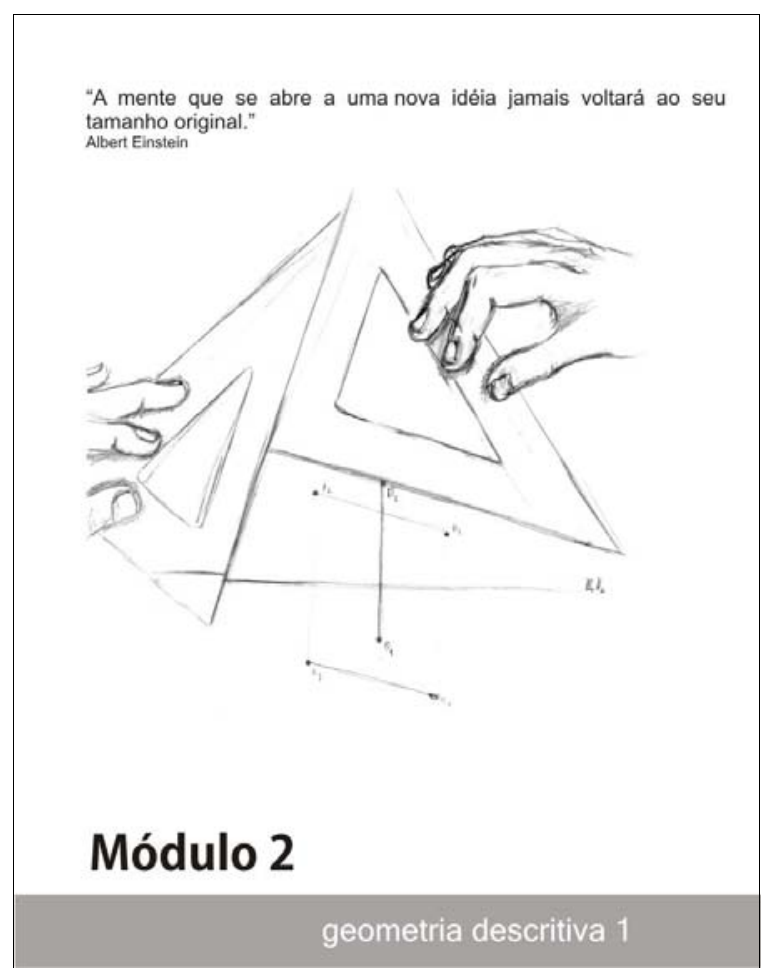


Por fim, no plano da superfície, as principais modificações realizadas dizem respeito às representações gráficas refeitas ou inseridas no material para auxiliar o aluno a melhor visualizar os conceitos e enunciados dos problemas a serem resolvidos.

Figura 14: Exemplo de exercício (no material original) com enunciado totalmente textual (exige que o aluno imagine a situação problema)

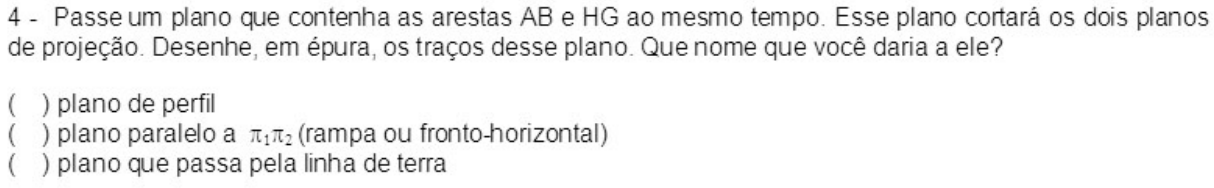

Figura 15: Exemplo de exercício (no material reformulado) com enunciado combinando texto e imagem (facilita a visualização da situação problema)

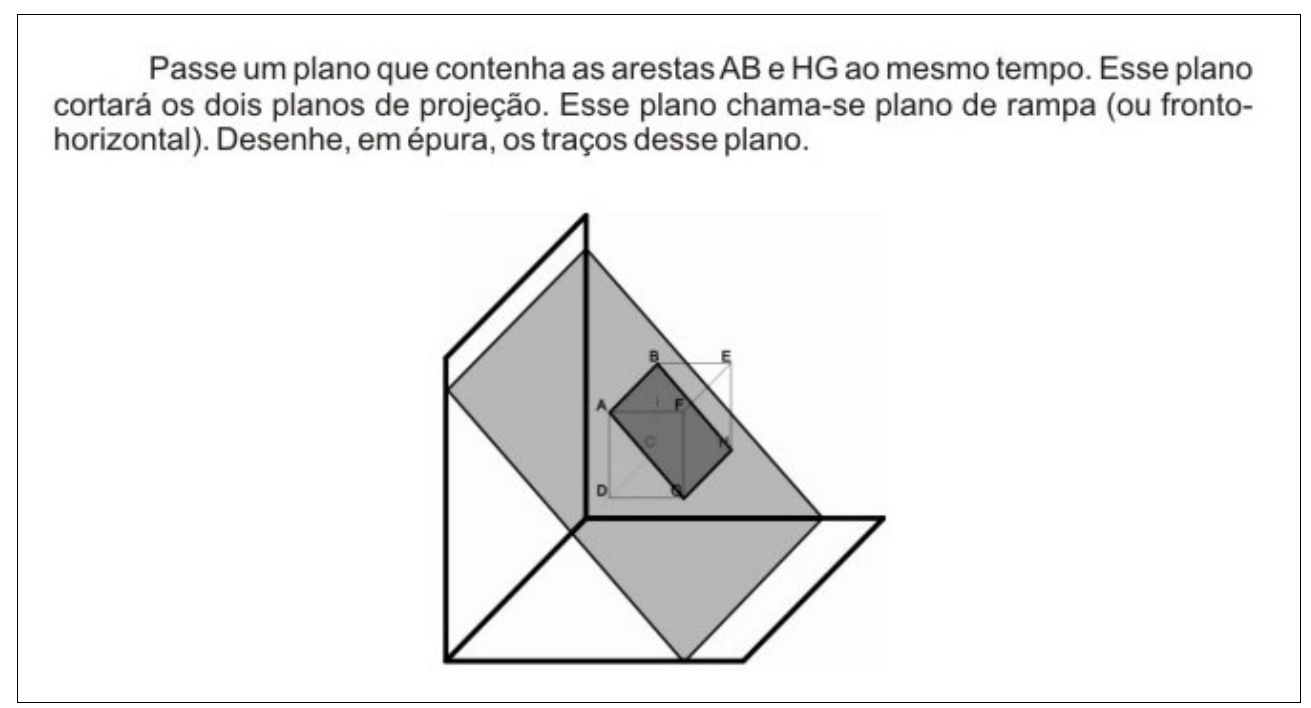

\section{Conclusões e desdobramentos}

A abordagem de design participativo mostrou-se bastante eficaz na elaboração desse material, oportunizando ainda aos alunos a aplicação de princípios de design da informação, além da prática de softwares gráficos típicos da profissão do designer.

Sendo o material desenvolvido mais dinâmico, os alunos sentem-se estimulados e, consequentemente, mais motivados para a disciplina. Observa-se um diálogo discente-discente, assim como discente-docente sobre a disciplina, surgindo frequentemente propostas de melhoramento. Tais propostas desencadearam também debates entre turmas de diferentes períodos com a intenção de melhorias do conteúdo assim como do design do material.

Cabe ainda mencionar a iniciativa de alguns alunos visando melhoria dos processos cognitivos relacionados ao aprendizado da visualização tridimensional. Várias propostas vêm sendo discutidas, dentre as quais a criação de artefatos concretos, demonstrando aspectos básicos da disciplina, como projeções, rebatimentos, etc. Uma das propostas integra aspectos lúdicos, outra demanda realização de pequenos projetos por parte dos alunos. A idéia seria conceber e construir artefatos que se relacionassem aos problemas da disciplina, estimulando, ao mesmo tempo, a interdisciplinaridade inerente à atividade, como, por exemplo, pesquisa sobre materiais e processos de fabricação.

O material reformulado continua sendo utilizado pelas turmas subseqüentes de Geometria 


\section{Infodesıgn}

Descritiva, assim como referência para outras disciplinas relacionadas.

\section{Agradecimento}

Os autores agradecem as professoras Vania Ribas Ulbricht e Marília Matos Gonçalves pela cessão do material original. O primeiro autor agradece também a seus alunos de GD1, turmas 2008.1 e 2008.2, da Universidade Tecnológica Federal do Paraná (UTFPR) por seu trabalho e colaboração na concretização deste projeto.

\section{Referências}

Bulhões, G. A. (2004). Ambiente hipermídia para aprendizado de geometria descritiva: módulo do estudo das posições relativas de duas retas entre si a ser implementado no Visual GD. Dissertação (Mestrado em Engenharia de Produção). Universidade Federal de Santa Catarina.

Cybis, W. A. (2003). Engenharia de usabilidade: uma abordagem ergonômica. Florianópolis: LabiUtil - UFSC.

Engelhardt, Y. (2002). The Language of Graphics. Amsterdam: ILLC.

Garrett, J. J. (2003). The elements of user experience. New York: AIGA | New Riders.

Gonçalves, M. M.; Ulbricht, V. R. (2006). Aplicação do Visual GD em situação real de ensino. In Anais do CONAHPA 2006. CD-ROM. p. 01-07.

Gonçalves, M. M. (2005). Análise das contribuições da aplicação do Visual GD de situação real de ensino. Tese (Doutorado em Engenharia de Produção). Universidade Federal de Santa Catarina.

Jacques, J. J.; Azevedo, G. Z.; Aymore, J. L. F.; Teixeira, F. G. (2001). Nova abordagem para o ensino de Geometria Descritiva básica. In Anais do COBENGE 2001. p. 417-422.

Kopke, R. C. M. (2001). Expressão Gráfica e Novos Meios Educativos - Ensino de geometria descritiva: inovando na metodologia. Revista Escola de Minas, vol. 54, no. 01.

Lima, H. G. G.; Costa, D. M. B. (2007). Desenvolvimento de um software para o aprendizado de Geometria Descritiva. In Anais do GRAPHICA 2007. CD-ROM.

Matlin, M. W. (2004). Psicologia cognitiva. São Paulo: LTC Editora.

Príncipe Júnior, A. R. (1983). Noções de geometria descritiva (v. 01). São Paulo: Nobel.

Santos, E T. (1999). Um applet para o ensino de geometria descritiva na internet. In Anais do XVII COBENGE. p. 2319-2326.

Silva, T. L. K.; Silva, R. P.; Teixeira, F. G. (2006). HyperCALGD on line - Projeto e desenvolvimento de objetos de aprendizagem para geometria descritiva. In Anais do COBENGE 2006. p. 16001613.

Silveira, J. E. C. (2007). Investigação de metodologia de ensino de geometria descritiva: uma experiência com estudantes de arquitetura e urbanismo. In Anais do GRAPHICA 2007. CDROM.

Teixeira, F. G.; Silva, R. P.; Silva, T. L. K.; Hoffmann, A. T. (2006). Geometria descritiva: aprendizagem baseada em projetos. In Anais do COBENGE 2006. p. 142-155.

Ulbricht, V. R. (1997). Modelagem de um ambiente hipermídia de construção do conhecimento em Geometria Descritiva. Florianópolis: UFSC, 1997. Tese (Doutorado em Engenharia de Produção). Universidade Federal de Santa Catarina.

Valente, V. C. P. N. (2003). Desenvolvimento de um ambiente computacional interativo e adaptativo para apoiar o aprendizado de Geometria Descritiva. Tese (Doutorado em Engenharia). Universidade de São Paulo.

Valente, V. C. P. N.; Santos, E. T. (2004). Ambiente Computacional para Apoio ao Aprendizado de Geometria Descritiva. In Anais do CONAHPA 2004. CD-ROM. p. 01-08.

Vieira, J. V. (2005). O ensino da geometria descritiva para alunos surdos apoiado em um ambiente hipermídia de aprendizagem - visual GD. Tese (Doutorado em Engenharia de Produção). Universidade Federal de Santa Catarina. 


\section{Sobre os autores}

Carlo Alessandro Zanetti Pece é pós-doutor pelo ITA, onde também obteve seu doutorado (2003), mestrado (1995) e graduação (1993). É professor adjunto e pesquisador do Departamento Acadêmico de Desenho Industrial da UTFPR. Seus interesses envolvem assuntos na interface entre o Design, a Ergonomia e a Engenharia. Professor Pece lecionou em diversas instituições, incluindo: Design em Brunel (Inglaterra), Engenharia Mecânica no ITA, UFPB e UFPE e Engenharia de Produção na UFPB. <carlo.pece@bol.com.br>

Stephania Padovani é graduada em Desenho Industrial pela ESDI-UERJ (1996), mestre em Design pela PUC-RJ (1998) e doutora em Ergonomia Cognitiva pela Loughborough University / Inglaterra (2001). É bolsista de Produtividade em Pesquisa do CNPq [nível 2], professora e pesquisadora do Departamento de Design e do Programa de Pós-graduação em Design da UFPR. Suas principais áreas de atuação são ergonomia da interação humano-computador, web design e design da informação, com enfoque nos temas de hipermídia, usabilidade de interfaces e métodos de design centrado no usuário. <s_padovani2@yahoo.co.uk>

Diego Mafioletti é estudante de graduação em Design da Universidade Tecnológica Federal do Paraná. É participante de um grupo de pesquisa que busca a inclusão de paraplégicos na informática. Seus interesses envolvem assuntos na interface entre o Design, a Ergonomia e a Engenharia. <diegomdesign@yahoo.com.br>

Anna Carolina Murata Galeb é estudante de graduação em Design pela Universidade Tecnológica Federal do Paraná. É monitora da disciplina de Geometria Descritiva na UTFPR. Seus interesses envolvem o debate sobre Design Social, Filosofia e Sociologia. <annacmg@gmail.com>

Pedro Serigheli da Rocha Paranhos é estudante de graduação em Design pela Universidade Tecnológica Federal do Paraná. Seus interesses envolvem o estudo da tipografia e comunicação visual. <pserigheli@hotmail.com> 